\title{
DESAHUCIADAS. Pobreza y lucro en la ciudad del siglo XXI
}

\section{EVICTED: Poverty and Profit in the American Cit}

\author{
Brythanye Bernales Rodriguez \\ Universidad Nacional Mayor de San Marcos \\ Brythanyg.bernales@unmsm.edu.pe
}

DESMOND, Matthew (2017)

Desahuciadas. Pobreza y lucro en la ciudad del siglo XXI

Traducción de Enrique Maldonado Roldán, edición original en inglés 2016.

Madrid: Capitan Swing, 464 pp. ISBN 978-84-946452-0-4

"Me siento sucio al recopilar estas historias y dificultades como si fueran trofeos" -escribe el sociólogo M. Desmond, rememorando el término de las investigaciones que darían vida a Desahuciadas, obra ganadora del premio Pulitzer de No ficción

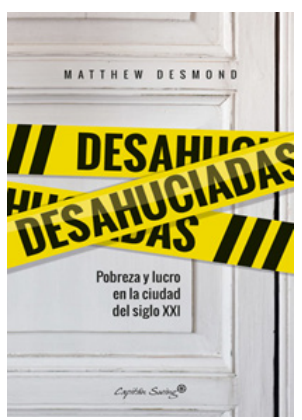
2017. No era para menos. Desmond se asentó en los barrios marginales de Milwaukee (Wisconsin, Estados Unidos) -primero en el Parque de Viviendas Móviles College en South Side y luego en un apartamento compartido en los guetos del North Side- entre mayo de 2008 y diciembre de 2009, para encontrar respuestas al evento que marcó la ruta de su familia cuando era apenas un niño: el desahucio. Lejos de tratarse de un episodio aislado, el desahucio -o desalojo legal forzado- es una experiencia que impacta en la vida pública y privada de cada vez un mayor número de familias de clase media y baja en los países llamados de «primer mundo", especialmente, tras la crisis financiera global de 2008. En ese sentido, Desahuciadas nos introduce en este gravitante problema a través de las vivencias habitacionales de ocho familias que pese a sus variantes constitutivas (número, género, etnia, formación u ocupación, entre otros) comparten el haberse visto atrapadas en el círculo de la pobreza por pretender aspirar a una vivienda que les brinde alojamiento «cual ratones en una ratonera».

Para comprender la pobreza en un país económicamente «desarrollado» y de consistente presencia estatal como Estados Unidos, es necesario, según el autor, hacer a un lado las concepciones que la ubican como el problema de un grupo apartado de la sociedad, «los pobres», y cuestionar las perspectivas que sostienen que la desigualdad es meramente producto de «fuerzas estructurales» distantes de nuestro control o de las «carencias individuales» de sus miembros en términos culturales o educativos ¿Por qué -se pregunta Desmond- hemos indagado en los medios con los que los pobres pueden «salir adelante»y no en el porqué de las altas sumas que registran sus facturas o hacia dónde se dirigen sus ingresos? La pobreza es una relación que implica igualmente a los pobres y a los ricos pese a las barreras territoriales que separan a los sociales, 1(2), 273 - 275. http://dx.doi.org/10.15381/espiral.v1i2.17146 
unos de los otros. Por tanto, la responsabilidad de su vigencia tras décadas de políticas asistenciales no puede situarse en su polo más débil, sino más bien, en el espectro de sus interrelaciones, y entre estas, el desahucio se presenta como un proceso central.

El desahucio como proceso involucra relaciones de lucha y dependencia entre arrendadores(as) y arrendatarios(as). Ambos actores emplean diversos recursos para sacar el máximo provecho de las viviendas que les pertenecen o los acogen, respectivamente, pero no afianzan vínculos con ellas debido a la inestabilidad de sus «posesiones». Los primeros porque se encuentran en búsqueda de viviendas que les otorguen mayor rentabilidad; y los segundos porque sus reducidos ingresos los colocan al límite de la supervivencia. Así, vemos en uno de los casos expuestos en el libro a Arleen, una madre soltera de dos hijos, quien se ve forzada a invertir más del $90 \%$ de sus ingresos en costear mensualmente el alquiler de un deteriorado apartamento -y con ello, a comprometer el alimento, vestido y educación de sus hijos- aún a sabiendas de sus escasas posibilidades de permanecer en esa vivienda el mes próximo; mientras que Sherrena, especialista en el alquiler de viviendas en los guetos, hace lo propio al tramitar con rapidez órdenes de desahucio cada vez que alguno de sus arrendatarios(as) pone «en peligro» su negocio -atrayendo a la policía, a inspectores de vivienda o a trabajadores sociales- $u$ incremente sus costos de inversión -solicitando la refacción de los servicios de agua y desagüe o la reparación de techos, paredes o pisos-.

La vivienda, sostiene Desmond, es una necesidad humana fundamental que afecta tanto a sus miembros internos como externos: «sin un alojamiento estable, el resto se desmorona». La estabilidad residencial genera cierto tipo de estabilidad psicológica que permite a las personas invertir esfuerzos en afianzar los vínculos al interior de sus familias y alrededor de su entorno inmediato, independientemente a su grupo etario, género o etnia. No obstante, Desahuciadas evidencia a la vez que los procesos de desahucio tienen un impacto más significativo entre las mujeres negras, los niños y las niñas. Es más, el poseer estas características reducen sus posibilidades de encontrar una nueva vivienda de alquiler en las semanas o meses siguientes. Asimismo, el recurrente número de desahucios provoca que sea imposible efectuar acciones colectivas entre los residentes de un barrio -rasgando el tejido social- y, en consecuencia, comunidades enteras se sumergen en condiciones deplorables de hábitat y habitabilidad. De igual modo, junto con la estabilidad, los desahucios también provocan pérdidas a las familias: no sólo pierden sus hogares, sino también su vinculación a colegios, empleos y posesiones de bienes muebles como artefactos, vestimenta o libros. Estas pérdidas se agravan debido a que la búsqueda de un nuevo hogar -y, en el mejor de los casos, el hallar una nueva residencia- requiere una considerable cantidad de dinero y de tiempo. Así, las «dificultades materiales» entre las familias desahuciadas pueden extenderse hasta al menos dos años después de la expulsión; y sus efectos psíquicos y cognitivos, permanecer el resto de sus vidas cuando no desencadenan la muerte.

Por otro lado, la mayoría de «los pobres» de la ciudad se encuentran excluidos no sólo de la propiedad de bienes inmuebles, sino también del acceso a las viviendas sociales. La insuficiencia de apoyo gubernamental, argumenta el autor, sumada a la tendencia al alza de los alquileres y del coste de los suministros y el estancamiento de los ingresos, es el motivo por el que la mayoría de las familias pobres en régimen de alquiler destinan la mayor parte de sus ingresos a la vivienda. Esta interdependencia privilegia el lucro de ciertos sectores poblacionales a costa de insertar familias enteras en un ciclo de empobrecimiento que vulnera su derecho fundamental a la vivienda, al tiempo que condena al abandono y la estigmatización a cada vez mayores áreas territoriales, y a la infrautilización de las capacidades colectivas de sus miembros. Para subvertir el ciclo de la pobreza en nuestras ciudades, concluye Desmond, resulta determinante volcar nuestra atención a las dinámicas del sector privado de vivienda 
y construir sobre esa base los nuevos lineamientos en las políticas de asistencia social y de vivienda pública.

Finalmente, además de una consistente propuesta académica, Desahuciadas nos instruye principalmente en tres aspectos: presentación de resultados, compromiso intelectual y agudeza investigativa. Respecto a la primera, Desmond conoce el impacto de la autoridad del autor en la escritura y, por consiguiente, en la información registrada, por lo que decide optar por el uso de la tercera persona gramatical, aunque esta no sea una línea habitual entre las publicaciones académicas. Por ello, Desahuciadas es un ejemplo de cómo en ciertas ocasiones es necesario evaluar nuestras narrativas, revelando así la importancia de la formación literaria entre los científicos sociales. En segundo lugar, nos encontramos con un investigador que no sólo elabora sus conclusiones desde el sentir de los sectores menos favorecidos -cuál preceptor de derechos y defensor de demandas-, sino que interpela por igual al conjunto de los actores involucrados y sólo desde ese lugar de enunciación visibiliza los problemas que atañen de fondo a las vidas de dichos sectores vulnerables. La tarea no es sencilla, en palabras de Desmond, la convivencia con los arrendadores(as) y arrendatarios(as) en Milwaukee bajo la premisa subyacente de realizar un «trabajo de campo» fue «un trabajo descorazonador que me deprimió durante años». Por último, además del intenso trabajo in situ, el sociólogo elaboró diversos recursos metodológicos que le permitieron observar factores determinantes en términos políticos. Entre ellos, resulta revelador el esclarecimiento de la concepción que los propios desahuciados manejan sobre el desahucio: "Cuando dices "desahucio" - argumentaba Rose, protagonista de otro de los casos expuestos en el libro-, yo pienso en los sheriffs que llegan y te echan y cambian las cerraduras, y los de Eagle [una de las prósperas empresas de mudanza en la localidad] que tiran tus cosas en la acera". Concepciones similares hacen imposible visualizar el alcance de los desahucios, pues no consideran todas las circunstancias bajo las cuáles los arrendatarios(as) experimentan la desposesión involuntaria de sus viviendas. De ahí, la relevancia de tales descubrimientos. También, en el capítulo de cierre, Desmond esboza importantes anotaciones sobre el trabajo etnográfico, de las cuales destacan dos: el reconocimiento de que la ignorancia no se reduce meramente al desconocimiento de ciertos aspectos de la vida por dificultades en el aprendizaje, sino que constituye una forma fundamental de estar en mundo, especialmente, entre los sectores más vulnerables de nuestras sociedades; y de las dificultades que conlleva la selección de unos casos por sobre otros bajo el impulso de pretender captar la atención del lector o despertar indignación o empatía en estos.

Por esta valiosa conjunción de atributos, Desahuciadas ha saldado con creces la deuda de nuestra indiferencia hacia arrendadores(as), arrendatarios(as) y respecto a quienes lucran con la pobreza en la ciudad al amparo de nuestras legislaciones. Esperamos que su lectura inquiete y conduzca a examinar nuestras propias realidades con mirada atenta y juiciosa. 


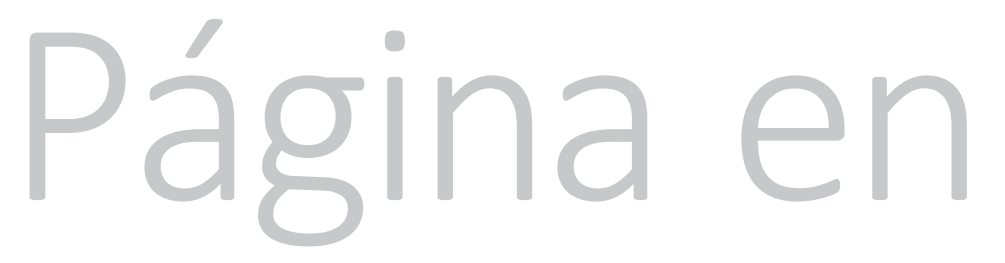

blanco 